CARDIOVASCULAR MEDICINE

\title{
Long term cardiovascular effects of oral antidiabetic agents in non-diabetic patients with insulin resistance: double blind, prospective, randomised study
}

\author{
D A Stakos, D P Schuster, E A Sparks, C F Wooley, K Osei, H Boudoulas
}

Heart 2005;91:589-594. doi: 10.1136/hrt.2003.027722

See end of article for authors' affiliations

.....................

Correspondence to: Dr Harisios Boudoulas, Centre for Clinical Research, Foundation of Biomedical Research, Academy of Athens, 4 Soranou Ephessiou St, 11527, Athens, Greece; boudoulas@ bioacademy.gr

Accepted 14 May 2004
Objective: To study the long term cardiovascular effects of oral antidiabetic agents in non-diabetic patients with insulin resistance.

Patients: 181 African American subjects with insulin resistance and normal glucose tolerance test were randomised to receive glipizide $5 \mathrm{mg} /$ day $(\mathrm{n}=25)$, metformin $500 \mathrm{mg} /$ day $(\mathrm{n}=59)$, or placebo ( $n=97$ ) for 24 months. Insulin sensitivity, glucose tolerance, lipid profile, left ventricular mass (echocardiography), aortic distensibility (echocardiography, blood pressure), aortic pulse wave velocity (PWV, carotid to femoral artery, Doppler) were measured at baseline and at 12 and 24 months after randomisation.

Results: A significant increase in PWV was observed in both glipizide (mean (SEM) change at 24 months $2.8(2.7) \mathrm{m} / \mathrm{s}, \mathrm{p}=0.012)$ and metformin $(2.2(0.7) \mathrm{m} / \mathrm{s}, \mathrm{p}=0.01)$ groups during the follow up period. In contrast, PWV remained unchanged in the placebo group. The increase in PWV in the treatment groups was significant compared with placebo (analysis of variance $p<0.05$ ). Other cardiovascular or metabolic variables did not change significantly compared with placebo during follow up.

Conclusions: The observed increase in PWV is consistent with a decrease in the elastic properties of the aorta. The use of oral antidiabetic agents for the prevention of cardiovascular complications in nondiabetic African Americans with insulin resistance needs to be critically evaluated.
1 sulin resistance may be present in non-diabetic individuals with a family history of non-insulin dependent diabetes mellitus (NIDDM), especially in African Americans. ${ }^{1-5}$ It has been suggested that improvement of insulin sensitivity in these high risk individuals may delay the development of NIDDM and its related cardiovascular complications. ${ }^{6}$ Interventions that may improve insulin sensitivity include lifestyle and dietary modification, weight reduction, exercise, and treatment with oral antidiabetic agents. $^{7-9}$

Biguanides and sulfonylureas are widely used for the treatment of NIDDM and have been used for the prevention of diabetes in non-diabetic patients. ${ }^{10}{ }^{11}$ Long term prospective randomised studies of the cardiovascular effects of these antidiabetic agents in non-diabetic individuals with insulin resistance are lacking.

In this prospective randomised double blind study, the long term effects of glipizide and metformin on multiple cardiovascular variables, metabolic parameters, and lipid profile in non-diabetic individuals with insulin resistance and a family history of NIDDM were studied.

\section{METHODS}

\section{Study population}

In the diabetes clinic of The Ohio State University we follow up about 3000 African Americans with NIDDM; patients recruited for the study were offspring of these patients. One hundred and eighty one non-diabetic African Americans with an age range of 25-63 years (mean (SD) 42 (8) years) were studied. All patients were offspring of at least one parent with NIDDM as defined by the National Diabetes Data Group criteria. ${ }^{12}$ Fasting plasma glucose was $<6.38 \mathrm{mmol} / \mathrm{l}$ and plasma glucose two hours after administration of $75 \mathrm{~g}$ oral glucose load was $<7.78 \mathrm{mmol} / \mathrm{l}$. The study was designed in
1994. At that time $6.38 \mathrm{mmol} / \mathrm{l}$ was considered the cut off value for normal fasting plasma glucose concentrations.

All patients had decreased peripheral action of insulin as defined by the insulin sensitivity index $\left(\mathrm{S}_{\mathrm{I}}\right.$ ) and normal blood pressure. African Americans usually have high concentrations of high density lipoprotein (HDL) cholesterol and low concentrations of triglyceride. For these reasons none of the participants were considered to have metabolic syndrome. ${ }^{13}{ }^{14}$

Subjects with a history of excessive alcohol use or liver, kidney, or heart diseases, as well as pregnant or current breastfeeding women were excluded from the study. Patients taking pharmacological agents with known effects on the cardiovascular system, glucose metabolism, or insulin concentrations were also excluded.

The study protocol was approved by the human subjects research review committee of The Ohio State University. Written informed consent was obtained from all subjects before enrolment into the study.

\section{Cardiovascular studies}

All individuals provided a history and underwent a physical examination including body weight and height measurements. Brachial artery pressure was measured by sphygmomanometry with subjects in the supine position. Pulse pressure was obtained by subtracting the diastolic from the systolic blood pressure.

All subjects underwent echocardiography with a model 77020 A device (Hewlett-Packard, Palo Alto, California, USA). Echocardiograms were recorded with subjects in the supine position. Parasternal long axis, apical four chamber, and apical two chamber views were obtained. An ECG was

Abbreviations: HDL, high density lipoprotein; LDL, low density lipoprotein; LV, left ventricular; NIDDM, non-insulin dependent diabetes mellitus; PWV, pulse wave velocity; $S_{1}$, insulin sensitivity index 
Table 1 Baseline characteristics of the study population

\begin{tabular}{|c|c|c|c|c|}
\hline & $\begin{array}{l}\text { Glipizide } \\
\text { ( } n=25)\end{array}$ & $\begin{array}{l}\text { Metformin } \\
(\mathrm{n}=59)\end{array}$ & $\begin{array}{l}\text { Placebo } \\
(n=97)\end{array}$ & p Value \\
\hline Age (years) & $44.4(9.0)$ & $40.5(7.0)$ & $41.0(7.0)$ & NS \\
\hline Men/women & $11 \% / 89 \%$ & $26 \% / 74 \%$ & $24 \% / 76 \%$ & NS \\
\hline Weight (kg) & $94.6(25.8)$ & $90.5(20.8)$ & $89.9(22.2)$ & NS \\
\hline $\mathrm{BSA}\left(\mathrm{m}^{2}\right)$ & $2.0(0.3)$ & $1.94(0.2)$ & $2.0(0.2)$ & NS \\
\hline $\mathrm{SBP}(\mathrm{mm} \mathrm{Hg})$ & $133(22.0)$ & $122(15.0)$ & $125.0(14.0)$ & NS \\
\hline $\mathrm{DBP}(\mathrm{mm} \mathrm{Hg})$ & $82(11.0)$ & $80.0(11.0)$ & $82.1(10.6)$ & NS \\
\hline Pulse pressure $(\mathrm{mm} \mathrm{Hg})$ & $50(15.5)$ & $42.8(12.6)$ & $44.2(11.0)$ & NS \\
\hline LV mass index $\left(\mathrm{g} / \mathrm{m}^{2}\right)$ & $129(35.7)$ & $123.0(23.6)$ & $127.0(29.2)$ & NS \\
\hline Ascending AoDist $\left(\mathrm{cm}^{2} / \mathrm{dyn} \times 10^{-6}\right)$ & $2.5(1.4)$ & $2.8(1.6)$ & $3.2(1.7)$ & NS \\
\hline Abdominal AoDist $\left(\mathrm{cm}^{2} /\right.$ dyn $\left.\times 10^{-6}\right)$ & $4.1(2.5)$ & $3.7(1.5)$ & $4.0(1.5)$ & NS \\
\hline Pulse wave velocity $(\mathrm{m} / \mathrm{s})$ & $9.9(2.7)$ & $10.1(1.9)$ & $9.6(2.4)$ & NS \\
\hline Fasting glucose $(\mathrm{mmol} / \mathrm{l})$ & $4.53(0.95)$ & $4.44(0.83)$ & $4.50(1.11)$ & NS \\
\hline 120 min glucose OGTT (mmol/l) & $5.41(1.40)$ & $5.39(1.0)$ & $5.76(2.04)$ & NS \\
\hline Fasting insulin $(\mu \mathrm{U} / \mathrm{ml})$ & $9.7(5.7)$ & $15.2(7.9)$ & $12.8(9.7)$ & NS \\
\hline $\mathrm{S}_{\mathrm{I}}\left(\mathrm{min}^{-1} / \mu \mathrm{U} / \mathrm{ml}\right)$ & $2.4(1.5)$ & $2.7(1.7)$ & $2.4(1.5)$ & NS \\
\hline Fasting C peptide (nmol/l) & $0.8(0.4)$ & $0.87(0.4)$ & $0.9(0.5)$ & NS \\
\hline Total cholesterol (mmol/l) & $5.0(0.71)$ & $4.69(0.89)$ & $4.64(0.87)$ & NS \\
\hline HDL cholesterol (mmol/l) & $1.39(0.32)$ & $1.12(0.25)$ & $1.28(0.35)$ & NS \\
\hline LDL cholesterol (mmol/l) & $3.08(0.77)$ & $2.89(0.9)$ & $2.76(0.98)$ & NS \\
\hline Triglycerides (mmol/l) & $1.12(0.7)$ & $1.12(0.69)$ & $1.29(1.75)$ & NS \\
\hline
\end{tabular}

recorded simultaneously with the echocardiogram. Data were recorded on SVHS format videotape with a model AG-7300 video recorder (Panasonic, Secaucus, New Jersey, USA) at a rate of 30 frames/s.

\section{Left ventricular mass}

Left ventricular (LV) diameters were measured according to the recommendations of the American Society of Echocardiography at end diastole and end systole in freeze frames from the two dimensional directed $M$ mode echocardiogram. ${ }^{15}$ Systolic and diastolic thickness of the LV posterior wall and the interventricular septum were measured at the same time in the cardiac cycle as the LV diameters.

LV mass was calculated from the formula LV mass $(\mathrm{g})=$ $\{[(\mathrm{LV}$ diastolic diameter $+\mathrm{LV}$ posterior wall diastolic thickness + interventricular septum diastolic thickness) ${ }^{3}-$ $\left.\left.(\text { LV diastolic diameter })^{3}\right] \times 1.05\right\}-13.6$, where 1.05 is the specific gravity of the myocardium. LV mass calculated this way overestimates the ventricular mass as measured at necropsy by $13.6 \mathrm{~g}$; consequently this amount should be subtracted from the calculated value. LV mass was corrected for body surface area $\left(\mathrm{g} / \mathrm{m}^{2}\right)$ to obtain LV mass index. ${ }^{16}$

\section{Aortic pulse wave velocity}

For the measurements of aortic pulse wave velocity (PWV), the Doppler flow velocities from the carotid and femoral arteries were recorded simultaneously with the ECG. Times from the beginning of the QRS complex to the upstroke of the carotid artery Doppler flow velocity and from the beginning of the QRS complex to the upstroke of the left femoral artery Doppler flow velocity were measured. PWV was calculated as the ratio of the time required for the pulsed wave Doppler velocity to travel from the carotid to the femoral artery, over the distance between carotid and femoral arteries. ${ }^{17} \mathrm{PWV}$ was measured by the same investigator blinded to the treatment status. The variability in PWV measurements is less than 5\%.

\section{Aortic distensibility}

Systolic and diastolic diameters of the ascending aorta were measured about $3 \mathrm{~cm}$ above the aortic valve in the two dimensional guided $\mathrm{M}$ mode echocardiographic tracings from the parasternal long axis view. Systolic aortic diameter was measured at the maximum anterior motion of the aortic root. Diastolic aortic diameter was measured before the opening of the aortic valve at the peak of the QRS complex in the simultaneously recorded ECG. The average of five beats was used for analysis. Systolic abdominal aortic diameter was measured at the maximum anterior motion of the aorta. Diastolic abdominal aortic diameter was measured $100 \mathrm{~ms}$ before the beginning of the anterior motion of the aorta. Aortic distensibility was calculated from the following formula ${ }^{17}$ : aortic distensibility $\left(\mathrm{cm}^{2} /\right.$ dynes $\left.\times 10^{-6}\right)=2 \times$ (systolic aortic diameter) - (diastolic aortic diameter)/ (diastolic aortic diameter $) \times($ pulse pressure $)$.

\section{Metabolic studies}

Body weight and height were measured every three months with subjects wearing an examination gown without shoes. Body surface area was calculated from the formula: body surface area $\left(\mathrm{m}^{2}\right)=\sqrt{[(\text { body weight }(\mathrm{kg}) \times \text { height }(\mathrm{cm})) /}$ 3600].

With subjects in the supine position, two intravenous needles were inserted into forearm veins and kept patent with $0.9 \%$ normal saline infusion. One intravenous line was used to draw samples and the other to administer glucose and insulin.

Plasma glucose concentrations were measured by the glucose oxidase method with a glucose autoanalyser (Beckman, Fullerton, California, USA). Insulin and C peptide concentrations were determined by a standard double antibody radioimmunoassay technique at the Core Laboratories of The Ohio State University Hospitals.

Lipid concentrations were measured in the core laboratory of the Ohio State University Medical Center. Low density lipoprotein (LDL) cholesterol was calculated by the Friedwald method. ${ }^{18}$

\section{Oral glucose tolerance test}

Each subject was instructed to ingest $250 \mathrm{~g}$ of carbohydrate in their regular meals for three days before the study. After a 10-12 hour overnight fast, all subjects ingested a $75 \mathrm{~g}$ oral glucose load (Koladex, Baltimore, Maryland, USA) in a total volume of $250 \mathrm{ml}$ over two minutes. Blood samples for serum glucose, insulin, and C peptide determinations were obtained 


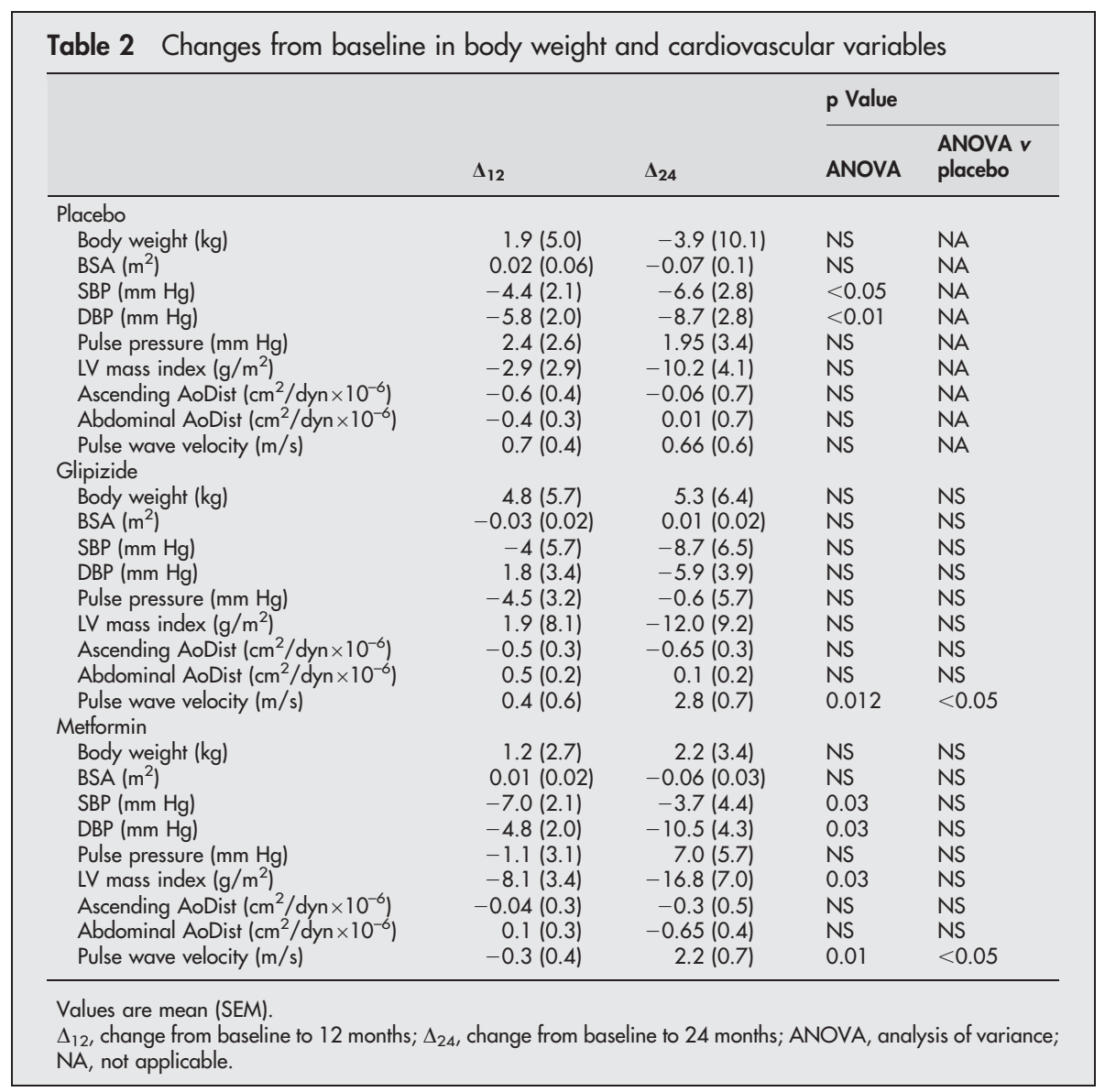

at baseline and at 30,60, 90, and 120 minutes after glucose administration. Glucose tolerance status was defined by the National Diabetes Data Group criteria. ${ }^{12}$

\section{Insulin sensitivity index}

$\mathrm{S}_{\mathrm{I}}$ was measured by the frequently sampled intravenous glucose tolerance test. Four blood samples were obtained at $-20,-15,-10$, and 0 minutes for basal plasma concentrations of glucose, $\mathrm{C}$ peptide, and insulin. The average of the four measurements was taken as the baseline value. Thereafter, $0.3 \mathrm{~g} / \mathrm{kg}$ glucose $(50 \mathrm{ml}$ of $50 \%$ dextrose water) was infused over a one minute period. Nineteen minutes after the completion of glucose administration (20 minutes total time), $0.05 \mathrm{U} / \mathrm{kg}$ insulin (Humulin, Lilly, Indianapolis, Indiana, USA) dissolved in $30 \mathrm{ml}$ of $0.9 \%$ normal saline was given intravenously over 60 seconds. $\mathrm{S}_{\mathrm{I}}$ was calculated by the minimal model software program (MINIMOD) described by Bergman and colleagues. ${ }^{19}$

\section{Study protocol}

After initial evaluation, all subjects were randomly divided into three groups and received glipizide $5 \mathrm{mg}(\mathrm{n}=25)$, metformin $500 \mathrm{mg}(\mathrm{n}=59)$, or placebo $(\mathrm{n}=97)$ once daily for 24 months. The shape of active drug tablets (glipizide and metformin) is different. For this reason for each active drug we created an identical placebo tablet. Thus, the total number of placebo was at least two to three times larger for any active treatment. Metformin was not approved by the US Food and Drug Administration at the beginning of the study and for this reason the metformin group was larger than the glipizide group. All subjects taking placebo were included together in the statistical analysis.

Systolic and diastolic blood pressure, PWV, ascending and abdominal aortic distensibility, LV mass index, fasting plasma glucose, C peptide, insulin, oral glucose tolerance test, $\mathrm{S}_{\mathrm{I}}$, total cholesterol, LDL cholesterol, HDL cholesterol, and triglycerides were measured at baseline and at 12 and 24 months after randomisation.

\section{Statistical methods}

Baseline measurements are presented as mean (SD) unless otherwise indicated. Changes from baseline to 12 months

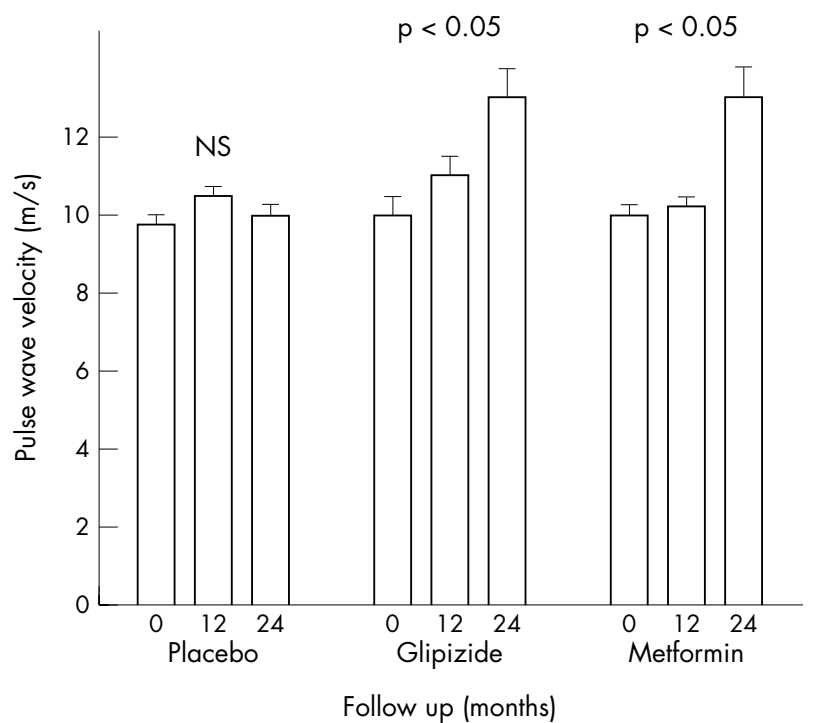

Figure 1 Changes in pulse wave velocity in metformin and glipizide groups were significant during the follow up period (analysis of variance (ANOVA) versus placebo). NS, not significant. 


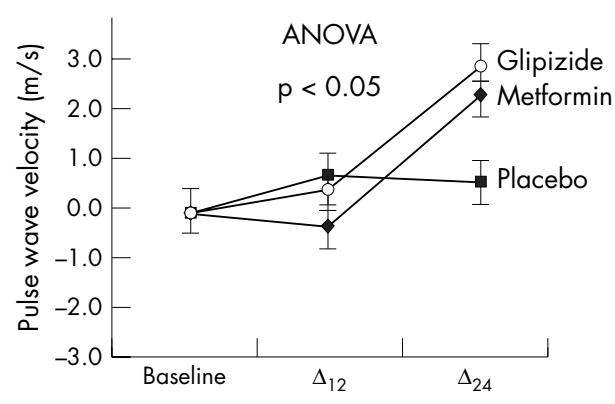

Figure 2 Changes in pulse wave velocity in metformin and glipizide groups were significantly greater than in the placebo group. $\Delta_{12}$, change from baseline to 12 months; $\Delta_{24}$, change from baseline to 24 months.

and from baseline to 24 months are presented as mean (SEM). Analysis of variance was used to define differences between the two groups during the follow up period and within each group. Multiple regression analysis was used to assess whether treatment was an independent predictor of changes in PWV during the follow up period. A probability value $\mathrm{p}<0.05$ was considered significant.

\section{RESULTS}

Table 1 presents the baseline clinical characteristics of the study population.

Both drugs were well tolerated and none of the subjects had any significant side effects. Serum glucose was unchanged in subjects taking active drugs during the study; as mentioned, the individuals had normal glucose tolerance to begin with. A previous study also showed that these drugs may slightly increase plasma glucose in normal people. ${ }^{20}$ The number of tablets was measured at each visit. For participation in the study, at least $80 \%$ compliance was required. A small number (about 13\%) of subjects dropped out. The reasons were failure to keep scheduled appointments, 50\%; medical reasons, 19\%; requested discontinuation, $8 \%$; relocation of the participant, $7 \%$; failure to take medication, $11 \%$; and pregnancy, $8 \%$.

\section{Follow up data}

Subjects in the metformin and placebo groups had a mild but significant decrease in systolic and diastolic blood pressure during the follow up period. Subjects in the glipizide group also had a mild, non-significant reduction in blood pressure.
These changes, however, were not significant compared with the placebo group. LV mass, ascending aortic distensibility, abdominal aortic distensibility, and PWV did not change significantly in the placebo group (table 2 ).

Glipizide treated subjects had a significant increase in PWV during the follow up period (analysis of variance $p=0.012$ ) (fig 1). None of any of the cardiovascular variables changed significantly (table 2). Likewise, PWV increased significantly in the metformin group during the follow up period (analysis of variance $p=0.01$ ) (fig 1 ). PWV in the placebo group remained unchanged. Furthermore, changes in PWV in the metformin and glipizide groups were significantly greater than in the placebo group (analysis of variance $\mathrm{p}<0.05$ ) (fig 2).

\section{Metabolic variables}

As expected, fasting serum insulin increased significantly $(p<0.01)$ in the glipizide group (table 3$)$. Fasting serum glucose, insulin, $\mathrm{C}$ peptide, and $\mathrm{S}_{\mathrm{I}}$ did not change significantly in any of the groups during the follow up period.

\section{Lipid concentrations}

Total cholesterol was slightly but significantly increased in the placebo group and remained unchanged in the metformin and glipizide treated subjects. No significant changes in HDL, LDL cholesterol, triglycerides, and total cholesterol to HDL cholesterol ratio were observed in any group during the follow up period (table 4).

\section{DISCUSSION}

In the present study two oral antidiabetic agents, a sulfonylurea (glipizide) and a biguanide (metformin), were administrated to non-diabetic African Americans with insulin resistance in a double blind fashion for 24 months. PWV increased significantly in both treatment groups after 24 months. In contrast, PWV remained unchanged in the placebo group. This increase in PWV in glipizide and metformin treated subjects was significant compared with the placebo group. Thus, long term administration of oral antidiabetic glipizide or metformin to normoglycaemic African Americans with insulin resistance may decrease the elastic properties of the aorta. It has been shown previously that increased PWV is an indicator of a high incidence of cardiovascular events and an independent predictor of cardiac mortality. ${ }^{21-25}$

The cause of this observation is not well understood. The two drugs used in the present study have different mechanisms of action but their glucose lowering effect is generally

Table 3 Changes from baseline in metabolic variables

\begin{tabular}{|c|c|c|c|c|}
\hline & \multirow[b]{2}{*}{$\Delta_{12}$} & \multirow[b]{2}{*}{$\Delta_{24}$} & \multicolumn{2}{|l|}{$\mathrm{p}$ Value } \\
\hline & & & ANOVA & $\begin{array}{l}\text { ANOVA } v \\
\text { placebo }\end{array}$ \\
\hline \multicolumn{5}{|l|}{ Placebo } \\
\hline Fasting serum glucose (mmol/l) & $0.18(0.22)$ & $0.10(0.21)$ & NS & NA \\
\hline Fasting serum insulin $(\mu \mathrm{U} / \mathrm{ml})$ & $1.53(2.22)$ & $1.8(2.26)$ & NS & NA \\
\hline $\mathrm{S}_{1}\left(\mathrm{~min}^{-1} \times \mu \mathrm{U} / \mathrm{ml}\right)$ & $0.13(0.23)$ & $0.43(0.36)$ & NS & NA \\
\hline Fasting C peptide (nmol/l) & $-0.17(0.08)$ & $-0.15(0.09)$ & NS & NA \\
\hline \multicolumn{5}{|l|}{ Glipizide } \\
\hline Fasting serum glucose $(\mathrm{mmol} / \mathrm{l})$ & $-0.43(0.49)$ & $0.19(0.61)$ & NS & NS \\
\hline Fasting serum insulin $(\mu \mathrm{U} / \mathrm{ml})$ & $5.7(2.1)$ & $10.4(2.7)$ & $<0.01$ & NS \\
\hline $\mathrm{S}_{\mathrm{I}}\left(\mathrm{min}^{-1} \times \mu \mathrm{U} / \mathrm{ml}\right)$ & $-0.65(0.4)$ & $-0.94(0.4)$ & NS & NS \\
\hline Fasting C peptide (nmol/l) & $-0.05(0.13)$ & $0.30(0.17)$ & NS & NS \\
\hline \multicolumn{5}{|l|}{ Metformin } \\
\hline Fasting serum glucose $(\mathrm{mmol} / \mathrm{l})$ & $0.34(0.25)$ & $0.43(0.28)$ & NS & NS \\
\hline Fasting serum insulin $(\mu \mathrm{U} / \mathrm{ml})$ & $2.7(2.5)$ & $2.3(2.4)$ & NS & NS \\
\hline $\mathrm{S}_{\mathrm{I}}\left(\mathrm{min}^{-1} \times \mu \mathrm{U} / \mathrm{ml}\right)$ & $0.1(0.3)$ & $-0.65(0.4)$ & NS & NS \\
\hline Fasting C peptide (nmol/l) & $0.66(0.51)$ & $-0.27(0.37)$ & NS & NS \\
\hline
\end{tabular}




\begin{tabular}{|c|c|c|c|c|}
\hline & \multirow[b]{2}{*}{$\Delta_{12}$} & \multirow[b]{2}{*}{$\Delta_{24}$} & \multicolumn{2}{|l|}{$\mathrm{p}$ Value } \\
\hline & & & ANOVA & $\begin{array}{l}\text { ANOVA v } \\
\text { placebo }\end{array}$ \\
\hline \multicolumn{5}{|l|}{ Placebo } \\
\hline Total cholesterol $(\mathrm{mmol} / \mathrm{l})$ & $0.228(0.136)$ & $0.527(0.118)$ & $<0.001$ & NA \\
\hline HDL cholesterol (mmol/l) & $0.127(0.062)$ & $0.119(0.047)$ & NS & NA \\
\hline LDL cholesterol (mmol/l) & $0.188(0.161)$ & $0.326(0.122)$ & NS & NA \\
\hline Triglycerides (mmol/l) & $-0.189(0.254)$ & $0.177(0.186)$ & NS & NA \\
\hline Total cholesterol:HDL & $0.17(1.8)$ & $0.07(0.14)$ & NS & NA \\
\hline \multicolumn{5}{|l|}{ Glipizide } \\
\hline Total cholesterol $(\mathrm{mmol} / \mathrm{l})$ & $-0.067(0.184)$ & $0.285(0.168)$ & NS & NS \\
\hline HDL cholesterol (mmol/li) & $0.041(0.109)$ & $0.044(0.098)$ & NS & NS \\
\hline LDL cholesterol (mmol/l) & $-0.212(0.207)$ & $0.168(0.189)$ & NS & NS \\
\hline Triglycerides (mmol/l) & $0.226(0.139)$ & $0.161(0.128)$ & NS & NS \\
\hline Total cholesterol:HDL & $0.1(0.4)$ & $0.14(0.3)$ & NS & NS \\
\hline \multicolumn{5}{|l|}{ Mefformin } \\
\hline Total cholesterol $(\mathrm{mmol} / \mathrm{l})$ & $0.254(0.137)$ & $0.179(0.132)$ & NS & NS \\
\hline HDL cholesterol (mmol/l) & $0.122(0.072)$ & $0.078(0.067)$ & NS & NS \\
\hline LDL cholesterol (mmol/l) & $0.298(0.155)$ & $0.399(0.142)$ & NS & NS \\
\hline Triglycerides (mmol/l) & $0.053(0.128)$ & $0.096(0.119)$ & NS & NS \\
\hline Total cholesterol:HDL & $0.1(0.2)$ & $0.3(0.1)$ & NS & NS \\
\hline
\end{tabular}

equivalent. Glipizide stimulates secretion of insulin from pancreatic $\beta$ cells and thus increases circulating insulin concentrations. In contrast to glipizide, metformin reduces hepatic glucose production in the presence of insulin and therefore is considered an insulin sensitiser. Indeed, in the present study fasting plasma insulin was significantly increased in glipizide treated subjects during the follow up period. In contrast, fasting plasma insulin concentrations remained unchanged in the metformin group. PWV, however, was increased significantly in both groups.

Twenty per cent of the participants were smokers. Smoking habit was equally distributed among the groups. Only a small number discontinued smoking during the study (about 5\% equally among groups). To show that changes in PWV were independent of smoking or other factors, a multiple regression analysis was performed. Age, sex, baseline systolic blood pressure, smoking status, $\mathrm{S}_{\mathrm{I}}$, total cholesterol, LDL cholesterol, LV mass, and fasting serum glucose were analysed. Treatment with oral antidiabetics was the only independent predictor of PWV changes during the follow up period $(\mathrm{p}=0.016)$. As mentioned previously, $6.38 \mathrm{mmol} / \mathrm{l}$ was considered the cut off value for normal plasma glucose concentrations in the present study. If we reanalyse the data with $6.1 \mathrm{mmol} / \mathrm{l}$ or even $5.55 \mathrm{mmol} / \mathrm{l}$ as the cut off, the results remain unchanged. PWV in this study was unrelated to plasma glucose. It is known that PWV increases with age. The time interval, however, was too short ( 24 months) to see any spontaneous changes.

The effect of metformin on systolic and diastolic blood pressures in non-diabetic patients with systemic hypertension is controversial and the long term effect of metformin or glipizide on blood pressure in non-diabetic patients with normal blood pressure is not well known. ${ }^{26}{ }^{27}$ In the present study all subjects had arterial blood pressure within normal limits. Individuals in the metformin and placebo groups had a mild but significant decrease in systolic and diastolic blood pressure during the follow up period. Subjects in the glipizide group also had a non-significant reduction in blood pressure. These changes, however, were not significant compared with the placebo group (analysis of variance). Subjects taking antihypertensive medication were excluded before entry into the study. However, participants in the study were instructed in lifestyle and dietary modifications, including moderate exercise and low salt intake. This may explain the mild reduction in blood pressure in all three groups.
It is known that pulse pressure (the difference between systolic and diastolic pressures) may provide a rough estimation of the elastic properties of the aorta. Indeed, pulse pressure was significantly related to PWV in the study population measured at baseline and at 12 months and 24 months $(\mathrm{p}=0.023, \mathrm{p}=0.0013$, and $\mathrm{p}<0.0001$, respectively). However, one way analysis of covariance showed that, unlike PWV, the effect of treatment on pulse pressure was not significant.

LV mass index was decreased slightly but significantly in subjects treated with metformin during the follow up period. This finding is in agreement with previous studies, where metformin was administrated to obese non-diabetic women with arterial hypertension for 12 weeks. ${ }^{26}$ It is known that glipizide has no effect on lipid profile, whereas metformin may have a favourable effect on plasma cholesterol concentrations. ${ }^{27-31}$ In the present study, however, no effect on lipid concentrations was observed in the metformin group after 24 months of treatment.

To our knowledge this is the first study to assess the long term cardiovascular effects of oral antidiabetic agents in nondiabetic individuals with insulin resistance and normal glucose tolerance. Two agents with different mechanisms of action were used prospectively in a double blind, placebo controlled fashion. All studied subjects were "healthy" with insulin resistance but a normal glucose tolerance test and no other disorder. During the 24 month follow up period there were no other treatment interventions. The precise mechanism(s) for the effect of the antidiabetic drugs on aortic function are not known. An effect of these drugs on smooth muscle cells or vasa vasorum flow of the aortic wall may provide a possible explanation. ${ }^{17}$ However, the precise responsible mechanism(s) are unknown. Changes in PWV may be affected by other factors. In a multivariate analysis, however, treatment with oral antidiabetics was the only independent predictor of changes in PWV during the follow up period.

A limitation of the study is that our data refer only to African Americans. Whether the observations of the present study may apply to other ethnic groups has not been defined.

In conclusion, a significant increase in PWV was observed in non-diabetic African Americans with insulin resistance treated with glipizide or metformin for 24 months. No significant changes in PWV were seen in the placebo group. No other cardiovascular variable changed significantly during 
the follow up period. On the basis of these observations, the use of glipizide, metformin, or both for the prevention of cardiovascular complication in normoglycaemic insulin resistant African Americans needs to be critically evaluated.

\section{ACKNOWLEDGEMENTS}

We thank the volunteers for the study and the registered nurses and dieticians in the GCRC, the Core Laboratory, and the NIH GCRCRR0034. The study was supported by grant NIH NIDDK DK 48127.

\section{Authors' affiliations}

D A Stakos, E A Sparks, C F Wooley, Division of Cardiology, The Ohio State University, Columbus, Ohio, USA

D P Schuster, K Osei, Division of Endocrinology, The Ohio State University

H Boudoulas, Centre for Clinical Research, Foundation of Biomedical Research, Academy of Athens, Athens, Greece

\section{REFERENCES}

1 Lillioja S, Mott DM, Spraul M, et al. Insulin resistance and insulin secretory dysfunction as precursors of non-insulin-dependent diabetes mellitus: prospective study of Pima Indians. N Engl J Med 1993;329:1988-92.

2 Eriksson J, Franssila-Kallunki A, Ekstrand A, et al. Early metabolic defects in persons at increased risk for non-insulin-dependent diabetes mellitus. N Engl J Med 1989:321:337-43.

3 Osei K, Cottrell DA, Orabella MM. Insulin sensitivity, glucose effectiveness, and body fat distribution pattern in nondiabetic offspring of patients with NIDDM. Diabetes Care 1991;14:890-6.

4 Haffner SM, Stern MP, Hazuda HP, et al. Increased insulin concentrations in nondiabetic offspring of diabetic parents. N Engl J Med 1988;319:1297-301

5 Haffner SM, D'Agostino R, Saad MF, et al. Increased insulin resistance and insulin secretion in nondiabetic African Americans and Hispanics compared with non-Hispanic whites. The insulin resistance atherosclerosis study. Diabetes 1996;45:742-8.

6 The Diabetes Prevention Program Research Group. The diabetes prevention program: design and methods for a clinical trial in the prevention of type 2 diabetes. The diabetes prevention program research group. Diabetes Care 1999;22:623-34

7 Wing RR, Venditti E, Jakicic JM, et al. Lifestyle intervention in overweight individuals with a family history of diabetes. Diabetes Care 1998;21:350-9.

8 Diabetes Prevention Program Research Group. Design and methods for a clinical trial in the prevention of type 2 diabetes. The diabetes prevention program. Diabetes Care 1999;22:623-34.

9 Nolan JJ, Ludvik B, Beerdsen P, et al. Improvement in glucose tolerance and insulin resistance in obese subjects treated with troglitazone. N Engl J Med 1994;331:1188-93.

10 Diabetes Prevention Program Research Group. Reduction in the incidence of type 2 diabetes with lifestyle intervention or metformin. Diabetes prevention program research group. N Engl J Med 2002;346:393-403.

11 Sartor G, Scheniken B, Carlstrom S, et al. Ten year follow up of subjects with impaired glucose tolerance: prevention of diabetes by tolbutamide and diet regulation. Diabetes 1980;29:41-9.

12 Anon. Report of the Expert Committee on the Diagnosis and Classification of Diabetes Mellitus. Diabetes Care 1997;20:1 183-97.
13 Ford ES, Giles WH, Dietz WH. Prevalence of the metabolic syndrome among US adults: findings from the third national health and nutrition examination survey. JAMA 2002;287:356-9.

14 Park YW, Zhu S, Panaiapan L, et al. The metabolic syndrome: prevalence and associated risk factors: findings in the US population from the third national health and nutrition examination survey. Arch Intern Med 2002;163:427-36.

15 Sahn DJ, DeMaria A, Kisslo J, et al. The committee on M-mode standardization of the American Society of Echocardiography. Recommendations regarding quantification in $\mathrm{M}$-mode echocardiography: results of a survey of echocardiographic measurements. Circulation 1978;58:1072-83.

16 Devereux RB, Reicher N. Echocardiographic determination of left ventricular mass in man: anatomic validation of the method. Circulation 1977;55:613-8.

17 Boudoulas H, Wooley CF. Aortic function. In: Boudoulas H, Toutouzas P, Wooley CF, eds. Functional abnormalities of the aorta. New York: Futura Publishing, 1996:17-22.

18 Friedwald WT, Levy RI, Fredrickson DS. Estimation of concentration of lowdensity lipoprotein cholesterol in plasma, without use of the preparative ultracentrifuge. Clin Chem 1972;18:499-502.

19 Bergman RN, Prager R, Volund A, et al. Equivalence of the insulin sensitivity index in man derived by the minimal model method and euglycaemic glucose clamp. J Clin Invest 1987;79:790-800.

20 Osei K, Rhinesmith S, Gaillard T, et al. Metabolic effects of glipizide gastrointestinal therapeutic system on serum glucose, insulin secretion, insulin sensitivity, and hepatic insulin extraction in glucose-tolerant, first degree relatives of African Americans patients with type 2 diabetes: new insights on mechanisms of action. Metabolism 2003:52:566-72.

21 Boutouyrie P, Tropeano Al, Asmar R, et al. Aortic stiffness is an independent predictor of primary coronary events in hypertensive patients: a longitudinal study. Hypertension 2002;39:10-5.

22 Asmar R, Rudnichi A, Blacher J, et al. Pulse pressure and aortic pulse wave are markers of cardiovascular risk in hypertensive populations. Am J Hypertens 2001;14:91-7.

23 Strandberg TE, Salomaa VV, Vanhanen HT, et al. Isolated diastolic hypertension, pulse pressure, and mean arterial pressure as predictors of mortality during a follow-up of up to 32 years. J Hypertens 2002;20:399-404

24 Laurent S, Boutouyrie P, Asmar R, et al. Aortic stiffness is an independen predictor of all cause and cardiovascular mortality in hypertensive patients. Hypertension 2001;37:1236-41.

25 Cruickshank K, Riste L, Anderson SG, et al. Aortic pulse wave velocity and its relationship to mortality in diabetes and glucose intolerance. Circulation 2002; 106:2085-90.

26 Giugliano D, De Rosa N, Di Maro G, et al. Metformin improves glucose, lipid metabolism, and reduces blood pressure in hypertensive, obese women. Diabetes Care 1993;16:1387-90.

27 Charles MA, Eschwege E, Grandmottet $P$, et al. Treatment with metformin of non-diabetic men with hypertension, hypertriglyceridaemia, and central fat distribution: the BIGPRO 1.2 trial. Diabetes Metab Res Rev 2000;16:2-7.

28 Sartor G, Ursing D, Nilsson-Ehle P, et al. Lack of primary effect of sulphonylurea (glipizide) on plasma lipoproteins and insulin action in former type 2 diabetics with attenuated insulin action. Eur J Clin Pharmacol 1987;33:279-82

29 Bergman M, Gidez LI, Eder HA. The effect of glipizide on HDL and HDL subclasses. Diabetes Res 1986;3:245-8.

30 Pentikainen PJ, Voutilainen E, Aro A, et al. Cholesterol lowering effect of metformin in combined hyperlipidemia: placebo controlled double blind trial. Ann Med 1990;22:307-12.

31 Carlsen SM, Rossvoll O, Bierve KS, et al. Metformin improves blood lipid pattern in nondiabetic patients with coronary heart disease. J Intern Med $1996 ; 239: 227-33$ 